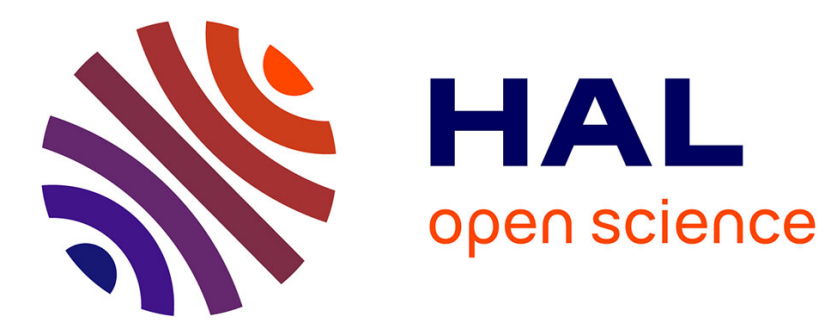

\title{
Analysis of the friction and wear behavior of hot work tool scale: application to the hot rolling process
}

C Vergne, Christine Boher, Christophe Levaillant, R Gras

\section{To cite this version:}

C Vergne, Christine Boher, Christophe Levaillant, R Gras. Analysis of the friction and wear behavior of hot work tool scale: application to the hot rolling process. Wear, 2001, 13th International Conference on Wear of Materials, VANCOUVER, CANADA, APR 22-26, 2001, 250 (1), pp.322-333. 10.1016/S0043-1648(01)00598-1 . hal-01717277

\section{HAL Id: hal-01717277 \\ https://hal.science/hal-01717277}

Submitted on 13 Dec 2018

HAL is a multi-disciplinary open access archive for the deposit and dissemination of scientific research documents, whether they are published or not. The documents may come from teaching and research institutions in France or abroad, or from public or private research centers.
L'archive ouverte pluridisciplinaire HAL, est destinée au dépôt et à la diffusion de documents scientifiques de niveau recherche, publiés ou non, émanant des établissements d'enseignement et de recherche français ou étrangers, des laboratoires publics ou privés. 


\title{
Analysis of the friction and wear behavior of hot work tool scale: application to the hot rolling process
}

\author{
C. Vergne ${ }^{\mathrm{a}, *}$, C. Boher ${ }^{\mathrm{a}}$, C. Levaillant ${ }^{\mathrm{a}}$, R. Gras ${ }^{\mathrm{b}}$ \\ a Ecole des Mines d'Albi Carmaux, Centre CROMeP, Campus Jarlard, Route de Teillet 81013, Albi CT Cedex 09, France \\ b ISMCM-CESTI, 3 Rue Fernand Hainaut, 93000 Saint-Ouen, France
}

\begin{abstract}
In hot forming processes, the interface tool/product is important for the quality of the finished product. In hot rolling, the scale formed on the roll material plays an essential role. As soon as the contact oxide-oxide is established between the roll and the slab, friction allows the process to start. However, the oxide scale will continue to grow under the cyclic action of hot contacts and water cooling and will be subjected to thermo-mechanical stresses. Beyond a certain critical thickness, the oxidized surface layer of the cylinders has not sufficient mechanical strength to withstand the shear stresses.

The wear and friction behavior of the oxides appearing on the surface of the hot working rolls is not well known. The influence of these oxides on the friction and, consequently, the quality of the products of finishing mills, seems very significant. So, in this study, we investigate the evolution of the friction coefficient and the wear, according to the growth, the nature and the thickness of the formed scale. We use a high temperature pin on disc tribometer. The pin consists of material "rolls" while the disc consists of the slab. The pin is instrumented with thermocouples in order to couple the friction coefficient measurements with the thermal gradient in the pin and the surface temperature and the formed oxides. Then, the characterization of the surfaces is done by scanning electronic microscopy (SEM) and EDS analyses. We use the method of $\sin ^{2} \Psi$ to evaluate residual stresses of oxide and correlate these data with shear stress behavior.
\end{abstract}

Keywords: Wear; Friction; Oxidation; Hot forming.

\section{Introduction}

The thermal cyclic working of tools in hot metal forming causes a superficial oxide scale. In thermo-mechanical working this scale grows to a critical thickness and then deteriorates and causes damage by inlaying and breakdown on the surfaces of rolled product and tools.

In hot rolling this oxide scale plays a major role because it allows the starting and the driving of the metal sheet between the rolls [1]. Without the generation of an oxide-oxide contact, much scuffing appears which is characteristic of a metal-oxide contact [2]. If a metal-metal contact is established at the start of mounting, the sheet is not pulled between the rolls what gives rise to sliding. For these reasons it is very interesting for the manufacturers to understand the birth and the growth of this oxide scale formed on the hot working rolls in or-

\footnotetext{
* Corresponding author. Fax: +33-563493242. E-mail addresses: vergne@enstimac.fr (C. Vergne), boher@enstimac.fr (C. Boher).
}

der to optimize the parameters of the process (pressure, speed, torque, etc.) and the quality of finished products.

The superficial damage of the tribological antagonists will depend on the nature and mechanical properties of oxides in the contact $[3,4]$. Thus, a hard oxide may give abrasive behavior whereas a ductile oxide may decrease the friction coefficient as well as the wear. The second factor often considered is the thickness of the oxide scale which is associated with adherence. Many studies have assessed the mechanical and tribological characteristics of the oxide scale formed on the rolled product, but the oxidation of rolls and its interaction with the strip are less reported. Nevertheless, one fact seems established: the coefficient of friction increases when the scale thickness decreases. The explanation of this remains controversial $[5,6]$.

The aim of this contribution is to correlate the evolution of the coefficient of friction with the appearance, the nature and the mechanical properties of the scales formed on hot metal working tools and their products. 


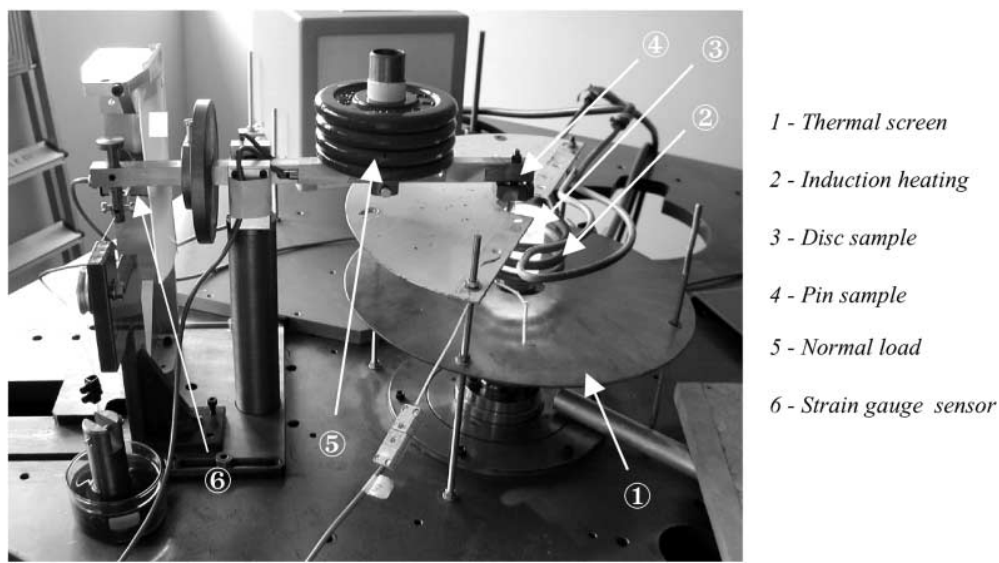

Fig. 1. High temperature pin on disc tribometer.

\section{Experimental equipment, materials, procedure and analysis}

\subsection{High temperature pin on disc tribometer}

A high temperature pin on disc tribometer was developed in our laboratory. The disc (Fig. 1-(3)) has a continuous rotating movement and the rotating speed can vary from 30 to $3000 \mathrm{rpm}$. Linear velocity depends upon radius of the wear track and ranges from 0.05 to $50 \mathrm{~m} / \mathrm{s}$ (Fig. 1). The disc can be heated to $1000^{\circ} \mathrm{C}$ by a high frequency induction heating system before rotation (Fig. 1-(2)). The homogeneity of the surface temperature of the disc is checked by spot-welded thermocouples. While in rotation, the disc temperature is controlled by an IR-pyrometer $\left(350-1400^{\circ} \mathrm{C}\right)$. A thermal screen protects the engine shaft (Fig. 1-(1)). The loading is carried out using dead weights (maximum capacity $100 \mathrm{~N}-$ Fig. 1-(5)). The tangential force is measured using a strain gauge placed parallel to the friction plane (Fig. 1-(6)). The friction coefficient is recorded with a software developed on LABVIEW. After test, wear surfaces are observed by optical microscopy and/or scanning electronic microscopy (SEM) with dispersive energy analysis.

The radius of curvature of the hemispherical pin was $20 \mathrm{~mm}$. The pins (Fig. 1-(4)) have been instrumented with two thermocouples located at 1 and $3 \mathrm{~mm}$ depths from the center of the pin contact. The temperatures in the pin have been continuously measured using a "Multireg C1732" SIEMENS recorder. The acquisition frequency is $3 \mathrm{~Hz}$. The initial arithmetic roughness of the discs was about $0.04 \mu \mathrm{m}$ $R_{\mathrm{a}}$. The disc was first heated up in rest to achieve the test temperature of $950^{\circ} \mathrm{C}$. The pin, which was initially at room-temperature was put on the disc. The rotation of the disc began (a) as soon as the pin was put on the disc, or (b) after stabilization of the temperature in the pin.

Test conditions are summarized in Table 1.

\subsection{Materials}

A white cast iron rich in carbides, called cast iron " $\mathrm{A}$ ", and a ferritic-pearlitic mild steel XC18 (AISI 1018) (Fig. 2a and $b$, Table 2) were examined. The cast iron had a high hardness of $63 \mathrm{HRC}(772 \mathrm{HV})$ and was brittle whereas the steel XC18 (AISI 1018) had a lower hardness of $168 \mathrm{HV}$.

The pin was always made of cast iron " $A$ " and the disc was always made of AISI 1018 mild steel. The pin represented the tool (roll material) and the disc represented the sheet (rolled product).

\subsection{Oxidation}

The oxidation of these alloys was studied. The purpose of these tests was to define a reference in thickness and to determine the nature of the oxide scales formed on the antagonists during the tribological tests. We performed phase

Table 1

Experimental conditions of tribological tests

\begin{tabular}{|c|c|c|c|c|c|}
\hline & Load $(\mathrm{N})$ & Sliding speed $(\mathrm{m} / \mathrm{s})$ & Test duration (s) & $\begin{array}{l}\text { Temperature of } \\
\text { the } \operatorname{disc}\left({ }^{\circ} \mathrm{C}\right)\end{array}$ & $\begin{array}{l}\text { Stabilizataion of the } \\
\text { temperature in the pin }\end{array}$ \\
\hline Series A & 2.5 & 0.05 & 3600 & 20 & - \\
\hline Series C & 2.5 & 0.05 & 3600 & 950 & No \\
\hline Series D & 10 & 0.05 & 3600 & 950 & No \\
\hline
\end{tabular}




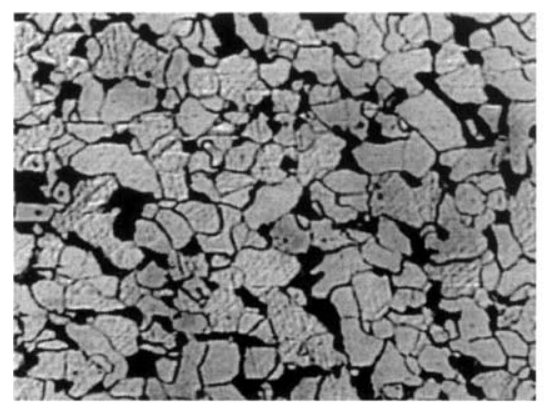

(a) Magnification : X 425

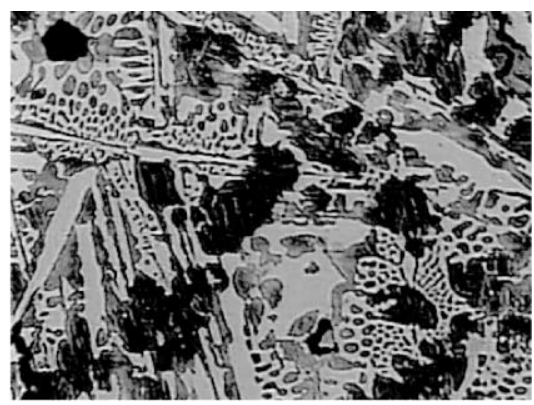

(b) Magnification : X 227.5

Fig. 2. Optical micrographs of AISI 1018 (a) and cast iron "A" (b).

Table 2

Chemical elements of materials.

\begin{tabular}{|c|c|c|c|c|c|c|c|c|c|c|c|}
\hline & Elements (wt.\%) & $\mathrm{C}$ & $\mathrm{Mn}$ & $\mathrm{Si}$ & $\mathrm{P}$ & S & $\mathrm{Cr}$ & $\mathrm{Ni}$ & Mo & $\mathrm{Nb}$ & $\overline{\mathrm{V}}$ \\
\hline Pin & Cast iron "A" & $3.2-3.5$ & - & $0.9-1.1$ & 0.109 & 0.077 & - & - & - & - & - \\
\hline Disc & XC18/AISI1018 & $0.16-0.22$ & $0.4-0.70$ & $0.15-0.35$ & $<0.035$ & $<0.035$ & $<0.40$ & $<0.40$ & $<0.1$ & - & - \\
\hline
\end{tabular}

${ }^{a}$ Cast iron "A": the total chemical composition of the case iron is confidential.

analysis on the samples in order to identify the nature of surface oxides.

Thermo-gravimetric analysis was done to study the oxidation kinetics. We used an electronic SETSYS thermobalance. The temperature was chosen to represent the friction test temperature and the various rolling temperatures. Different holding times were selected. The heating and cooling rates were 20 and $50^{\circ} \mathrm{C} / \mathrm{min}$, respectively.

\subsubsection{Oxide scale phase analysis}

The X-rays were used to determine the different nature of the oxide scale on the pin and on the disc after oxidation. Measurements were made with a diffractometer in the configuration $\theta-2 \theta$. The sample turned with a speed $\omega$ and the detector turned with a speed $2 \omega$. The rotation of the sample and the detector unit was continuous or step-by-step. A linear detector with $\mathrm{Cr} \mathrm{K} \alpha$ rays was used. The collimator beam

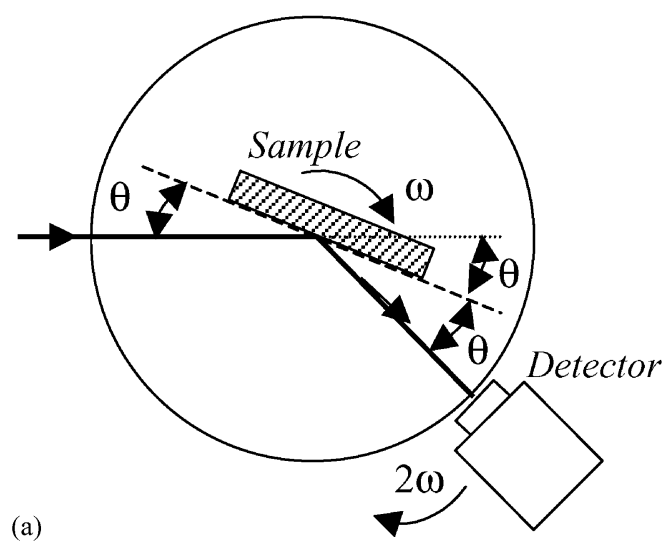

diameter was about $800 \mu \mathrm{m}$. The acquisition time was $3 \mathrm{~h}$ and the range of the scanning angle was $15-160^{\circ}$ (Fig. 3a).

\subsubsection{Residual stress calculation}

In crystalline structures, $\{h k l\}$ planes are characterized by interplanar spacing $d(h k l)$. A residual stress introduces a variation of the lattice parameter and of the interplanar spacing $d(h k l)$. This variation produces modifications of $\theta$, the diffraction angle. If $\lambda$, the wavelength of the X-ray, is constant, the microscopic deformation of the crystal lattice is given by

$$
\begin{aligned}
& \frac{\Delta d}{d}+\frac{\Delta \sin \theta}{\sin \theta}=0 \\
& \text { and } \\
& \varepsilon_{\text {micro }}=\frac{\Delta d}{d}
\end{aligned}
$$

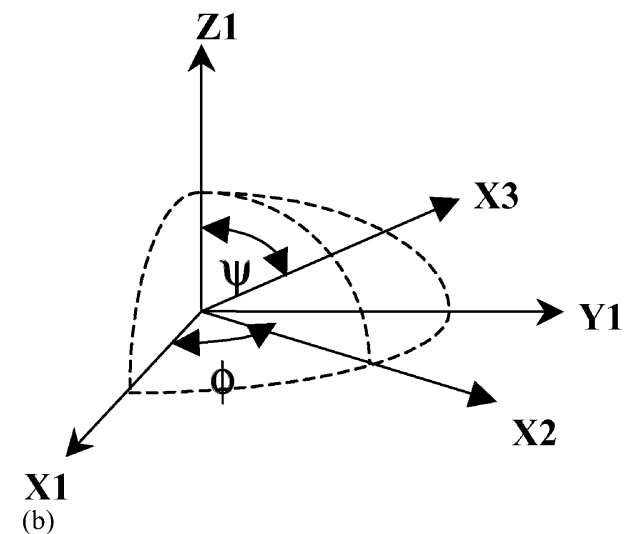

Fig. 3. (a) Principle of a X-ray diffractometer; (b) rotation of the reference frame in terms of $\psi$ and $\phi$ angles, with (X1, Y1, Z1) sample references. 
A well-known classical X-ray residual stress measurements using the $\sin ^{2} \psi$ technique was used [7]. Details of this method can be found in [8]. It can be summarized by the following expression for an isotropic material:

$$
\begin{aligned}
\Delta\left[2 \theta_{\phi, \psi}(h k l)\right]= & \left(-\frac{1}{2} S_{2(h k l)} \sigma_{\phi} \frac{2}{\cot g \theta}\right) \sin ^{2} \psi \\
& +S_{1(h k l)}\left(\sigma_{1}+\sigma_{2}\right) \frac{2}{\cot g \theta}
\end{aligned}
$$

where $(\phi, \psi)$ is the measurement directions, $\{h k l\}$ the diffraction planes, $\Delta\left[2 \theta_{\phi, \psi}(h k l)\right]$ the Bragg angle stress induced variation, $\sigma_{1}$ and $\sigma_{2}$ the principal stresses, $\sigma_{\phi}$ the stress in the direction $\phi$ and $12\left(S_{2}(h k l)\right)$ and $S_{1}(h k l)$ the $\mathrm{X}$-ray elastic constants. Changes in the Bragg angle correlate with residual stresses.

The apparatus is the Set-X equipped with a linear detector having an angular accuracy of $0.09^{\circ}$. The goniometer can make an angular movement of $\pm 180^{\circ}$ for the $\phi$ angle and an angular movement of $\pm 44^{\circ}$ for the $\psi$ angle (Fig. 3b). To measure deformation in the oxide scale, a supply voltage of $20 \mathrm{kV}$ and an intensity of $4.5 \mathrm{~mA}$ were used. Vanadium $\mathrm{K} \alpha$ radiation was used. The acquisition duration, for each peak (value of $\psi$ angle) took 15 or $30 \mathrm{~min}$. The penetration depth of the beam in the oxide is about $5-10 \mu \mathrm{m}$.

\section{Results}

\subsection{Nature and thickness of oxide scales}

For the mild steel, the analysis of oxidized samples was given in Fig. 4a. Oxide scale basically consisted of hematite. The intensity of peaks in the diffraction spectrum of hematite was not in agreement with JCPDS cards. In addition, some peaks could not be detected. The difference in intensity is assumed to be caused by the fact that the hematite is not statistically isotropic, i.e. that it was not composed of fine

(a)

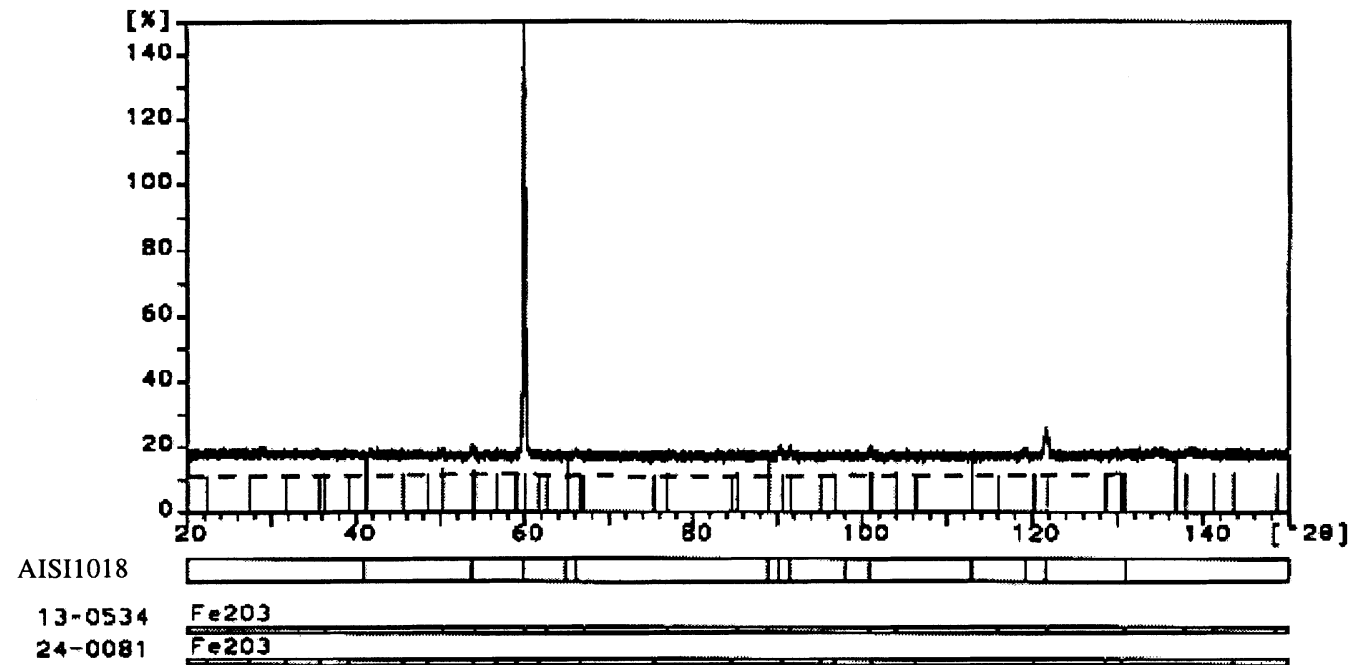

(b)

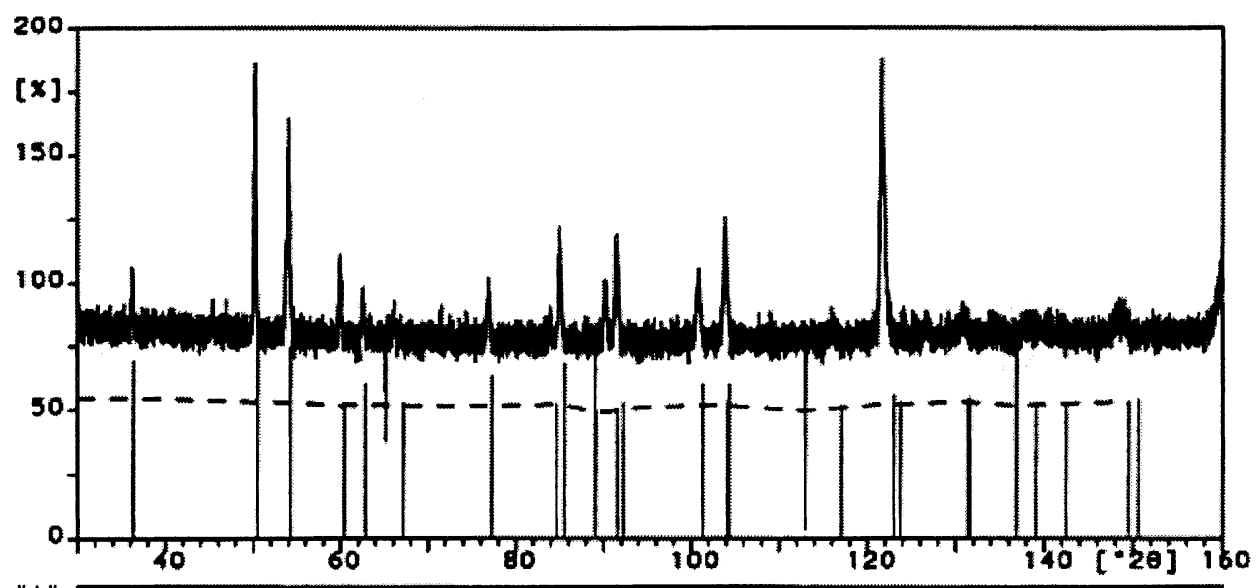

Cast iron "A"

$34-0412$

$(F \cdot 0.6 \mathrm{CrO} 0.4) 203$

Fig. 4. XRD traces obtained from AISI 1018 samples (a) and cast iron "A" samples (b). 


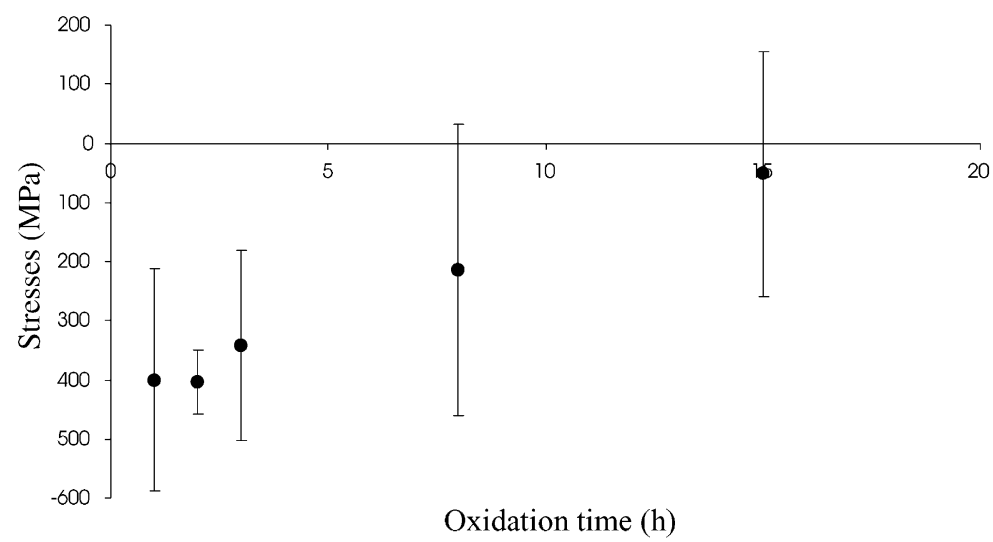

Fig. 5. Calculated compressive stresses of scale formed on AISI 1018 samples at $900^{\circ} \mathrm{C}$ for the (119) plane.

grains distributed in a random way. So, we can conclude that hematite with a preferential direction has been formed on the surface of our samples.

On the surface of cast iron "A" samples oxidized at $900^{\circ} \mathrm{C}$ for $24 \mathrm{~h}$, we observed peaks for hematite and peaks for chromite $\mathrm{FeCr}_{2} \mathrm{O}_{4}$ or to a compound $\left(\mathrm{FeO}_{6}, \mathrm{CrO}_{4}\right)_{2} \mathrm{O}_{3}$ (Fig. 4b). The chromite peaks are observed at the base of hematite peaks. So, the hematite on the cast iron "A" samples is much less textured than that observed on the surface of XC18 samples.

According to [5], the AISI 1018 steel has parabolic oxidation kinetics with regard to the time and an exponential dependence on temperature. In the range of temperature studied, between 900 and $1000^{\circ} \mathrm{C}$, the thickness of the scale formed on the AISI 1018 samples increases linearly. So we can suppose that the oxide scale which is formed at $900^{\circ} \mathrm{C}$ has a thickness of about $50 \mu \mathrm{m}$ after $1 \mathrm{~h}$ and about $70 \mu \mathrm{m}$ after $2 \mathrm{~h}$.

\subsection{Residual stresses in an oxide scale}

Residual stresses in different oxide scales were measured for AISI 1018 samples oxidized at $900^{\circ} \mathrm{C}$ for different oxidation times [9]. Whatever the testing time, two peaks were detected versus $\psi$ angle. The hematite texture phenomenon is responsible for the presence of two peaks. These two diffraction peaks correspond to the (1 119$)$ and (1 010$)$ planes. The internal stresses have, thus, been calculated for each family of planes. We made measurements with a small $\psi$ angle to characterize the residual stresses in (1 010$)$ planes and with a large $\psi$ angle to identify stresses for (119) plane. Fig. 5 shows the results of the calculated internal stresses for (1 1 19) planes. So we have observed.

- There are residual stresses in the hematite layer. The initial compressive residual stresses due to the preparation of samples were not considered because such stresses are relaxed when the samples are heated beyond the austenitic temperature. (a)

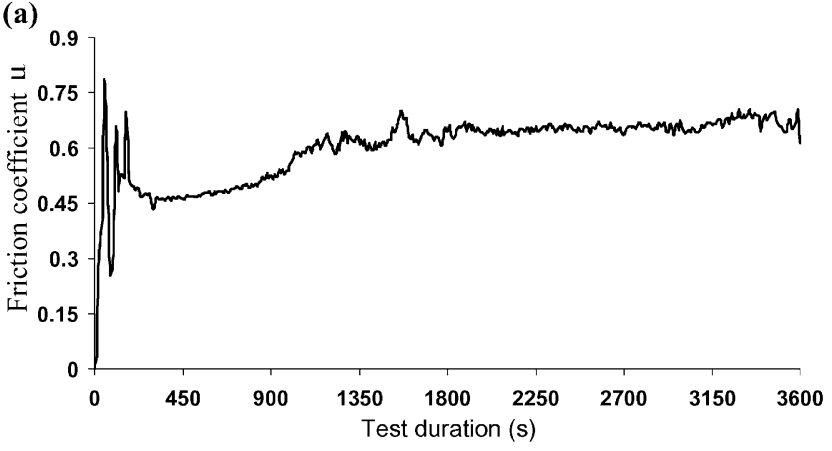

(b)

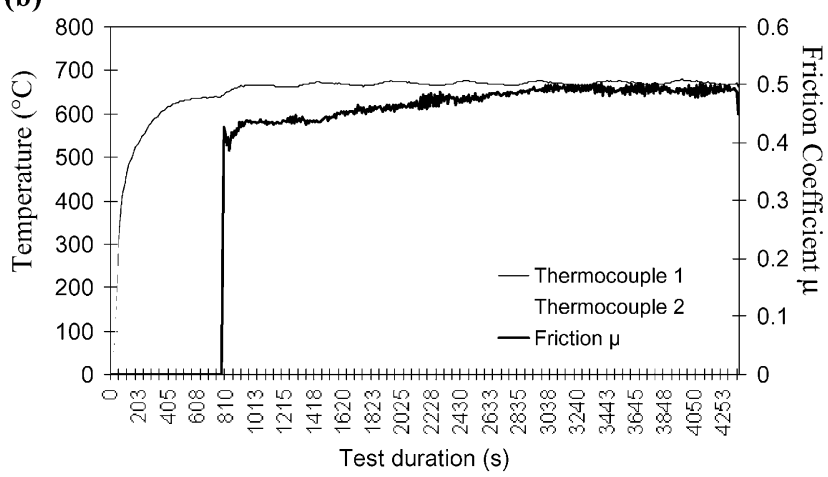

(c)

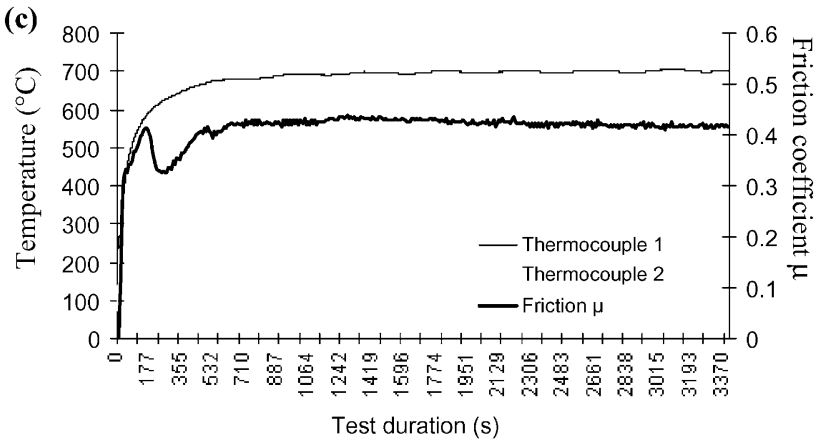

Fig. 6. Evolution of friction coefficient vs. testing time $-F_{n}=2.5 \mathrm{~N}$, $v=0.05 \mathrm{~m} / \mathrm{s}$ : (a) at room temperature, (b) $950^{\circ} \mathrm{C}$, with stabilized temperature in the pin, (c) $950^{\circ} \mathrm{C}$, without stabilized temperature in the pin. 
- The measured residual stresses are compressive as described by the following analytical model (Eq. (4)).

- The stress relaxation by cracking or buckling of oxide scale does not completely release the residual stresses even if some residual stresses approach zero. The same observation was made for the (1 01010$)$ planes.

The internal stresses within the oxide scales were calculated by an analytical model $[10,11]$. The effect of stresses related to the growth of the oxide scale and stress relaxation in the substrate were not taken into consideration. The thermal stresses seem to play the major role. We can write them as

$\sigma_{\text {th }}=\frac{E_{\mathrm{ox}} /\left(1-v_{\mathrm{ox}}\right)\left[\alpha_{\mathrm{ox}}(T)-\alpha_{\mathrm{s}}(T)\right] \Delta T}{1+\left(h_{\mathrm{ox}} / h_{\mathrm{s}}\right)\left(E_{\mathrm{ox}}(T)\left(1-\vartheta_{\mathrm{ox}}\right) / E_{\mathrm{s}}(T)\left(1-v_{\mathrm{s}}\right)\right)}$

where $E_{i}, v_{i}, \alpha_{i}$ and $h_{i}$ are the Young's modulus, Poisson's ratio, the thermal-expansion coefficient and the thickness of the substrate (s) or the oxide scale (ox).

We can use this model because the value $h_{\mathrm{ox}} / h_{\mathrm{S}}$ is not negligible. Considering the fact that the oxide scale mainly consists of hematite, the calculated residual thermal stress value (Eq. (4)) is about $550 \mathrm{MPa}$, which is close to the stress measured by $\mathrm{X}$-rays at room temperature $(\sigma \approx 400 \mathrm{MPa})$.

\subsection{Tribological results}

Three types of tribological tests were carried out according to the experimental conditions described in Table 1 .
At room temperature (series A), the mean value of the friction coefficient " $\mu$ " of the couple cast iron " $\mathrm{A}$ "/XC18 is $0.60 \pm 0.02$. Literature [12] gives a friction coefficient about 0.3 for cast iron on cast iron. In our case, the friction coefficient is close to the value generally found for steel on steel friction without lubrication. The presence of carbides in our cast iron could explain this elevated value. The friction evolution versus test duration includes a non-stationary period (Fig. 6a). This evolution could be characteristic of the mechanical accommodation of the couple cast iron "A"/XC18

In high temperature experiments $\left(950^{\circ} \mathrm{C}\right)$, the friction coefficient versus test duration evolution was different depending on the temperature stabilization time in the pin before sliding. The main difference between these two types of tests was in the non-stationary period. When the temperature in the pin was stabilized before sliding (series B), the pin thermocouples gave a temperature equal to $700^{\circ} \mathrm{C}$ at a depth of $1 \mathrm{~mm}$ from the contact surface, and equal to $670^{\circ} \mathrm{C}$ at a depth of $3 \mathrm{~mm}$ (Fig. 6b). In this case, the friction coefficient measured at the start of the test was in the same order of magnitude as the established one. The duration of the non-stationary period of the friction was not significant. So, the average value of the coefficient of friction was $0.46 \pm 0.01$. In the second case (series $C$ ), where we did not wait for the temperature stabilization in the pin before sliding, we observed that the coefficient of friction had two periods, the first one ranging between the test beginning and around $900 \mathrm{~s}$, the second one beyond $900 \mathrm{~s}$ (Fig. 6c). The first period is considered as a non-stationary period and the other one is a quasi-stationary period. We note that the non-stationary period corresponds to the duration of stabi-

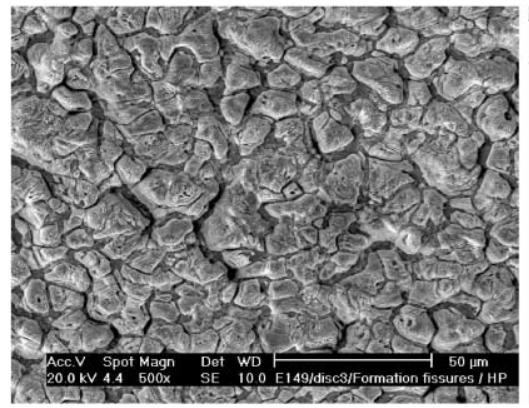

(a)

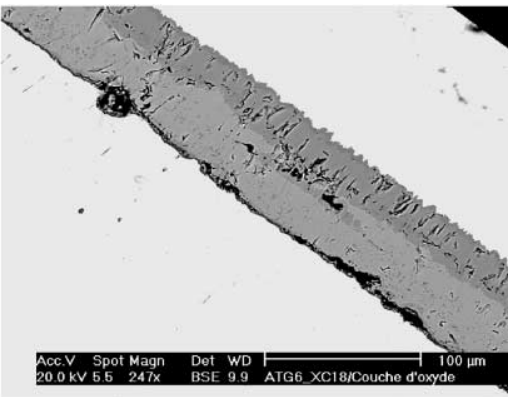

(b)

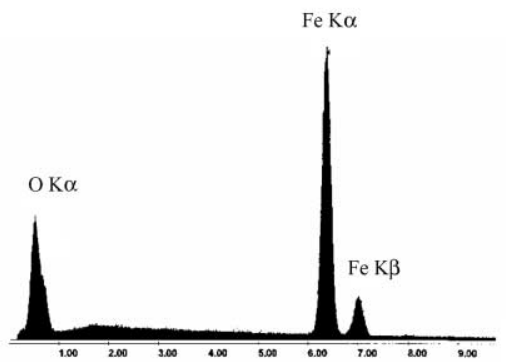

(c)

Fig. 7. (a) Disc micrograph - oxide scale feature out of the sliding contact surface; (b) disc micrograph - columnar-like microstructure of oxide scale; (c) disc analysis - EDX spectrum of the oxide scale columnar-like microstructure. 


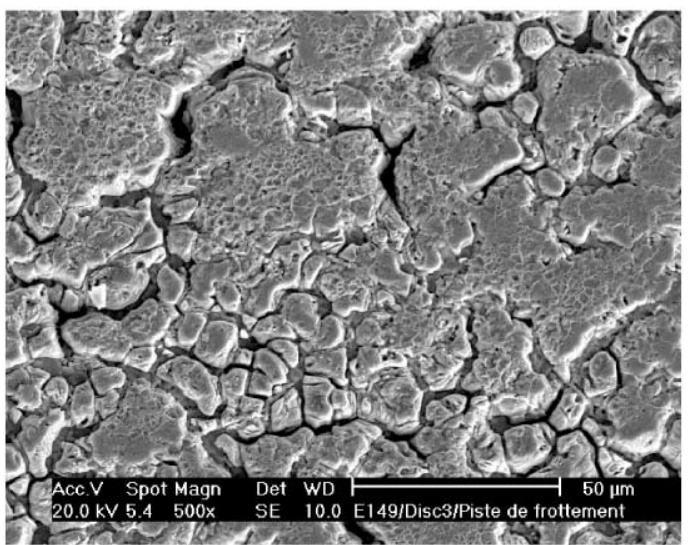

(a)

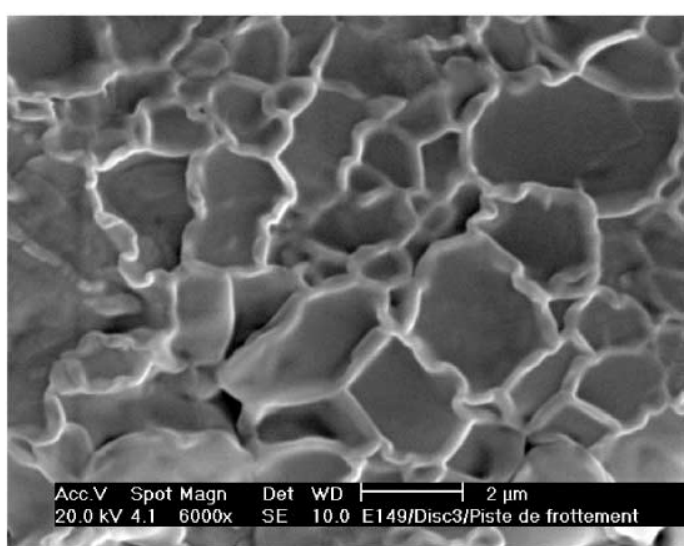

(b)

Fig. 8. (a) Disc micrograph — plastic deformation of the oxide scale columnar-like microstructure; (b) disc micrograph - "under-cells" with oxidized boundaries.

lization of the temperature in the pin and in this case, there is a large variation of the friction coefficient. In the stationary part, the average value of the coefficient of friction is $0.44 \pm 0.02$, so it is equal to the average value during the first tests (series B).

The same friction evolution is noted when we increase the load (series D), but in the stationary part, the average value of the coefficient of friction is lower 0.37.

When the temperature in the pin was stabilized before sliding, we could consider that the contact in the beginning of the sliding was oxide on oxide. In the second case, without stabilization, the contact was cast iron on oxide. In fact, the thickness of the natural oxide layer formed on the cast iron at room temperature is negligible.

\subsection{SEM micrographs and EDX spectra}

For all friction tests carried out at $950^{\circ} \mathrm{C}-$ with or without stabilization of the temperature in the pin - the AISI 1018 discs as the cast iron "A" pins have identical macroscopic wear surface features after $1 \mathrm{~h}$ test duration.

On the AISI 1018 discs, out of the friction surface, the oxide scale presents a columnar like micro-structure (Fig. 7a and $b$ ). The boundaries between columns are more or less broad and deep, and some could indicate cracks. EDX spectra of these columns reveals that it is iron oxide (Fig. 7c). SEM micrographs of the disc wear surface reveal that the real surface of contact is much lower than the apparent one. In addition, two types of contact can be observed depending on their localization in the friction zone. Outside of the wear scar, plastic deformation of the column is visible (Fig. 8a). The EDX spectrum shows that this bearing pressure area is made only of iron oxide. With a higher magnification, Fig. 8b shows that this plastically deformed area shows "under-cells" whose boundaries are also oxidized. For instance, the metallurgical reason of this microstructure is not well understood. Lastly, we can also observe an area on which plastically deformed material is transferred (Fig. 9) and identified by EDX spectra as being only iron oxide. In the center of the wear scar, there are zones made of aggregates at the top of which plastically deformed oxide layers are found (Fig. 10a). EDX analysis reveals that these layers are always made only of iron oxide, whereas the aggregates present iron, oxygen as well as traces of $\mathrm{Mn}$ and $\mathrm{Ni}$ (Fig. 10b).

A test of the series $C$ was stopped after 500 s sliding. Surface observations have revealed in the disc wear track small agglomerated crystals zones (Fig. 11a and b), not plastically deformed. EDX analysis shows that these crystals consist primarily of oxygen and iron, but also of $\mathrm{Nb}, \mathrm{Mn}, \mathrm{V}$ and $\mathrm{Cr}$. These crystals could be $\mathrm{Nb}, \mathrm{V}, \mathrm{Cr}$ and Fe carbides which would be oxidized.

With regard to the cast iron pins, three zones are observed. The first one, out of the wear track, has an acicular micro-structure (Fig. 12), made up only of iron oxide, which looks like needles of hematite $\mathrm{Fe}_{2} \mathrm{O}_{3}$. During the high temperature tribological test, this part is the coldest zone of the pin. The pin is hemispherical and this zone is not affected

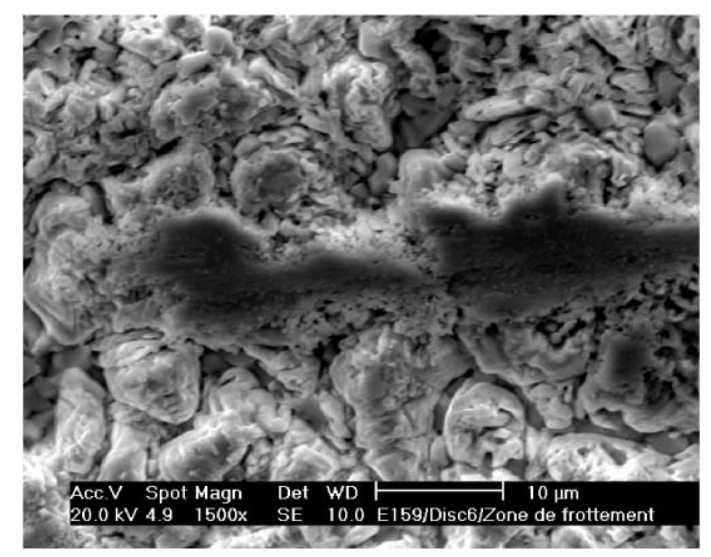

Fig. 9. Disc micrograph - material transfer on the disc wear track. 
(a)

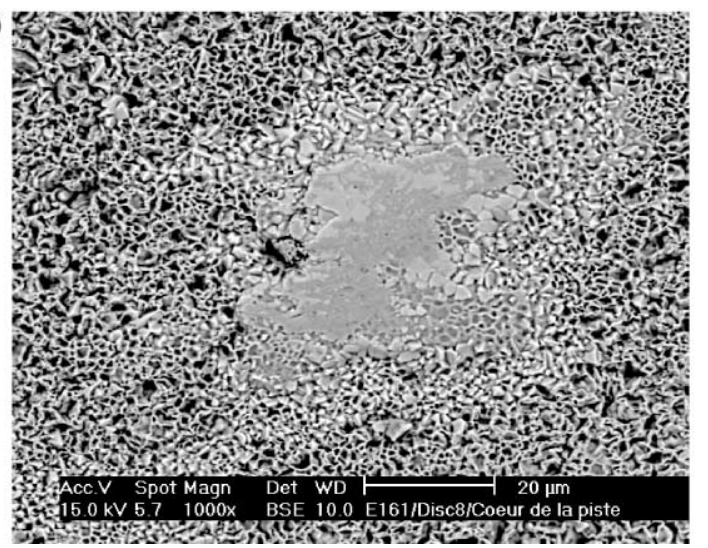

(b)

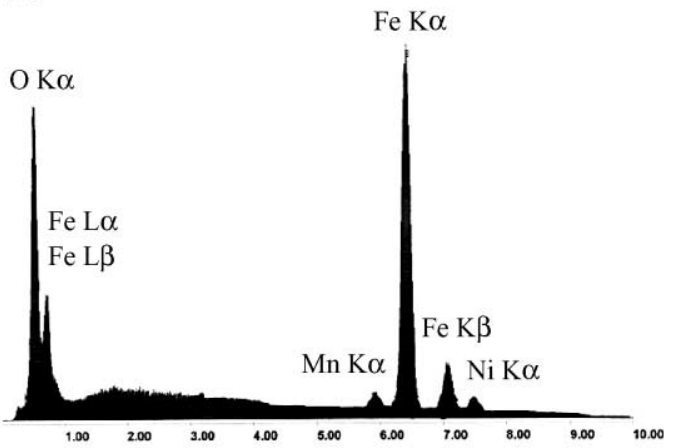

Fig. 10. (a) Disc micrograph - observation of the wear feature in the friction surface center; (b) disc analysis - EDX spectrum of the aggregates around the plastically deformed layer.
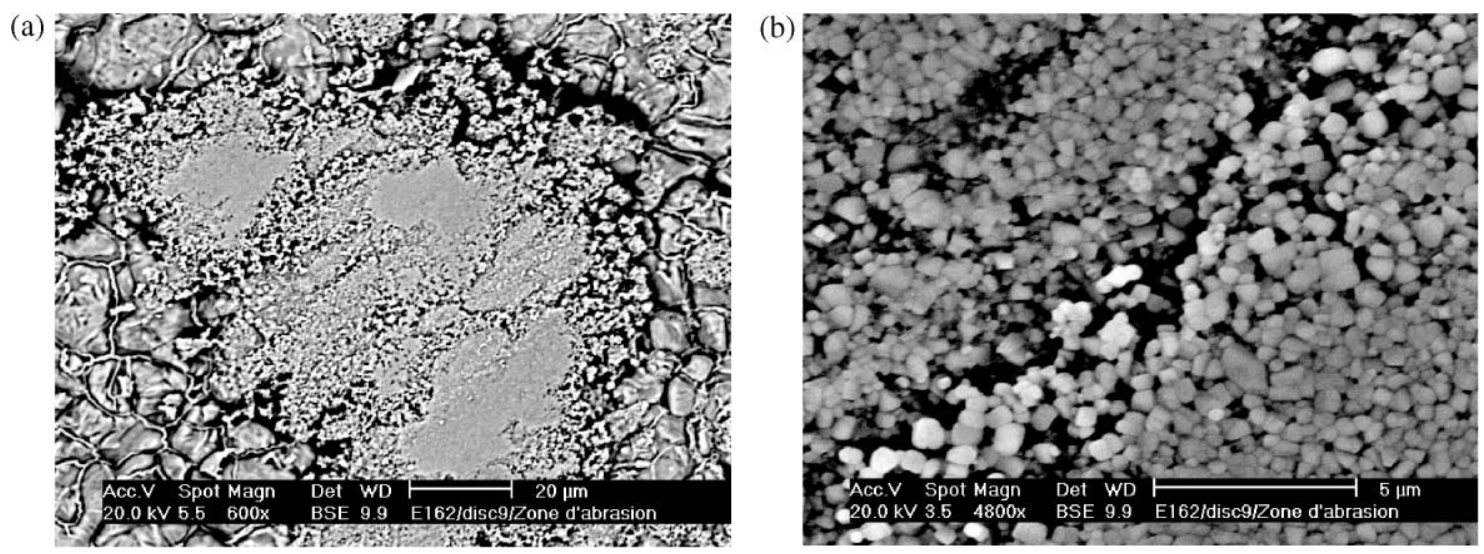

Fig. 11. (a) Disc micrograph - observation of small agglomerated crystals zones not plastically deformed; (b) disc micrograph - magnification of the agglomerated crystals zones.

by friction. Near the wear track, SEM micrographs reveal a microstructure like a sponge or nodules made up of agglomerated particles (Fig. 13). The first microstructure is a form of iron oxide, while the second one exhibits iron, oxygen, $\mathrm{Cr}, \mathrm{V}$ and $\mathrm{Mn}$. We can also see some excrescences of

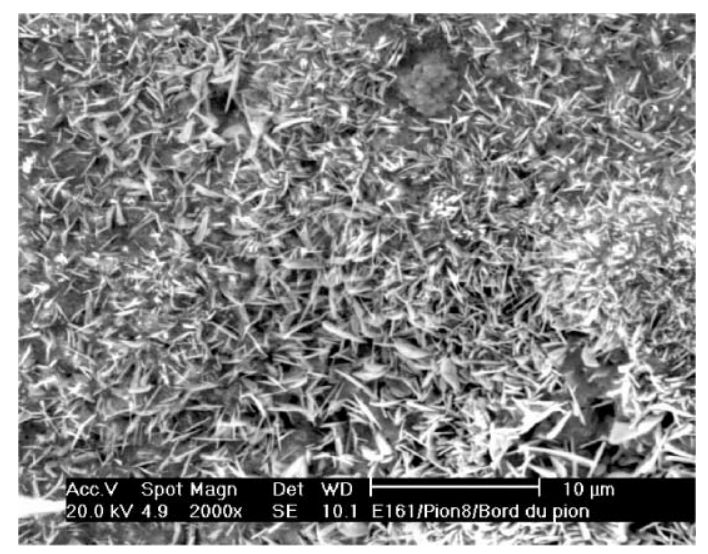

Fig. 12. Pin micrograph - acicular microstructure of the oxide scale out of the wear track. the scale (Fig. 14a), rich in Nb (Fig. 14b). There could be oxidized niobium carbide from the cast iron " $\mathrm{A}$ ".

Macroscopically, the shape of the pin friction surface is ellipsoidal and the large diameter is perpendicular to the direction of sliding. In the center of this surface, the wear track

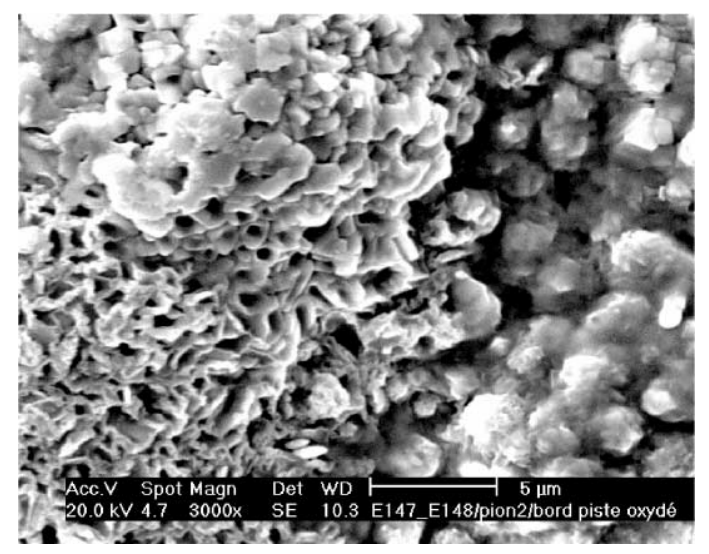

Fig. 13. Pin micrograph - observation of the two oxide microstructures (sponge and nodule). 
(a)

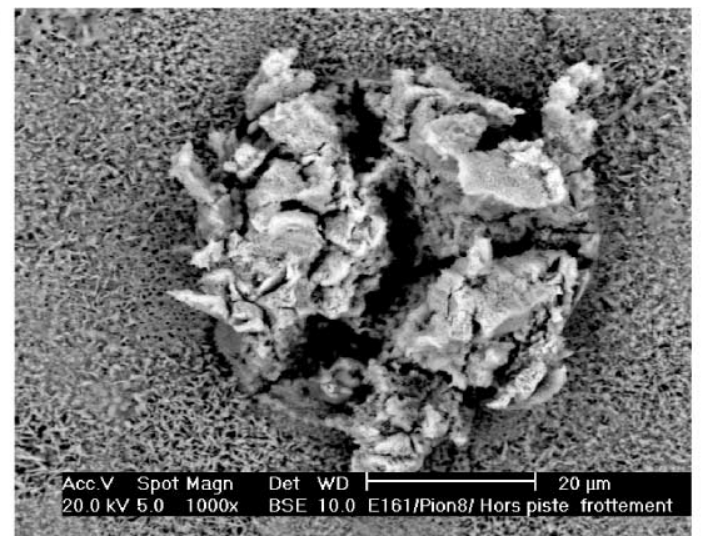

(b)

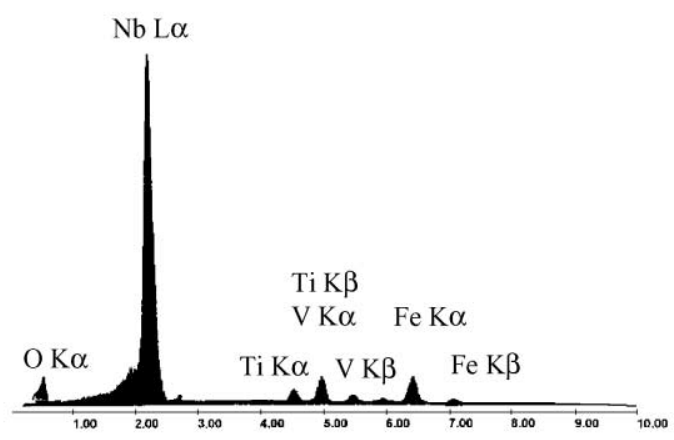

Fig. 14. (a)Pin micrograph - excrescences of the scale rich in Nb; (b) pin analysis - EDX spectrum of the excrescences of the scale.

is not uniform, with an alternation of zones of contact and zones without contact (Fig. 15a). Furthermore, the real contact surface is lower than the macroscopic apparent contact surface. Moreover, plastic deformation of the zone of contact is also observed. This area is made of a layer of iron oxide, plastically deformed and sustained by nodules (Fig. 15b).

These plastically deformed layers seem to be superficial and they do not affect the oxide scale thickness
(Fig. 15c). In the limits of the pin wear zone, SEM examinations show that the initial excrescences of oxide coatings, rich in $\mathrm{Nb}$, take place during friction phenomena (Fig. 14a before friction and Fig. 16 after friction).

Finally, if the test duration was longer, perhaps more zones of debris cracking and debris formation could appear in these plastically deformed zones (Fig. 17). (a)

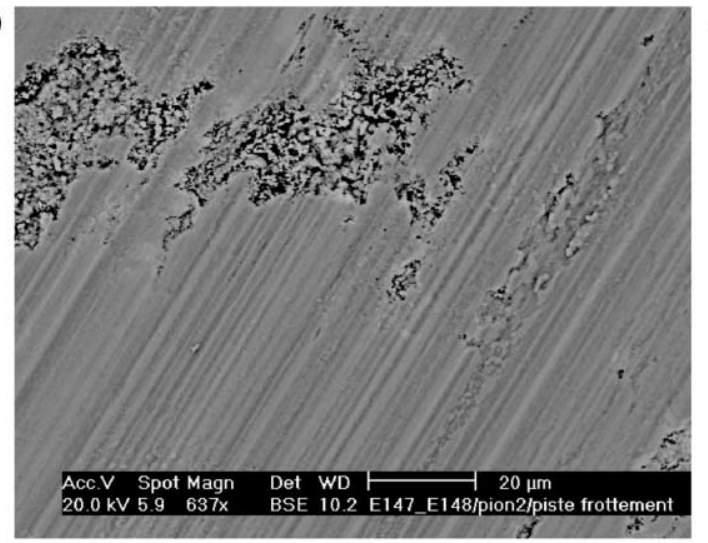

(b)

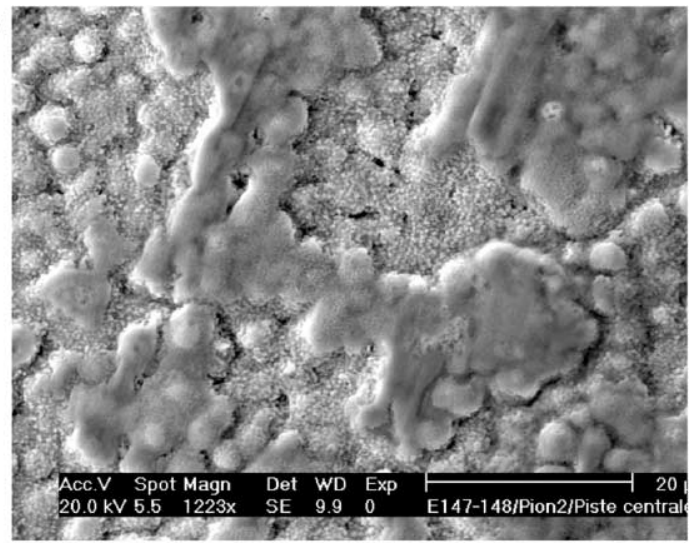

(c)

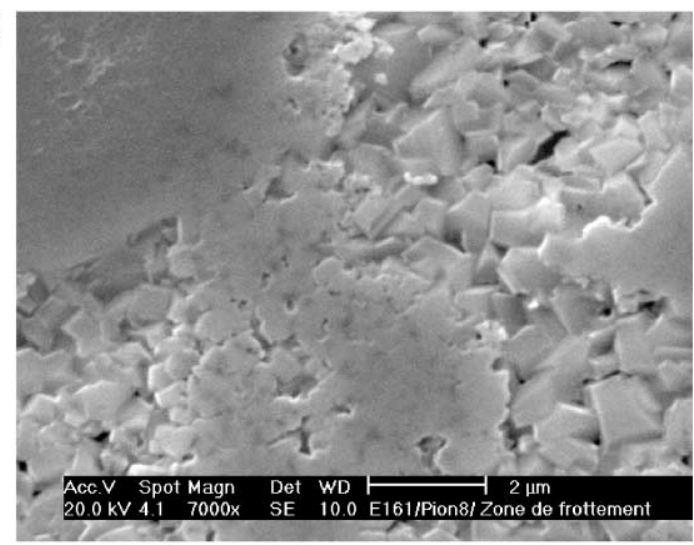

Fig. 15. (a) Pin micrograph - pin wear track with contact and no contact zones; (b) pin micrograph - plastically deformed layer of iron oxide, and sustained by nodules; (c) pin micrograph - superficial plastic deformation of the wear track. 


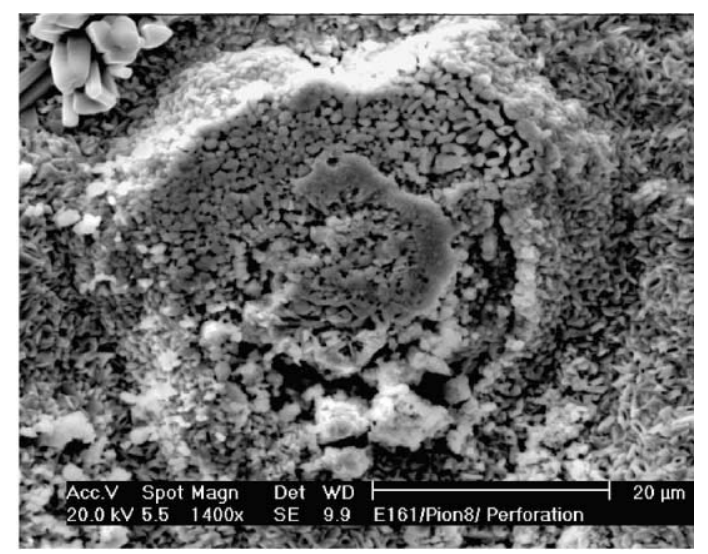

Fig. 16. Pin micrograph - participation of an excrescency in the friction.

\section{Discussion}

\subsection{Nature and mechanical properties of oxide scales}

The thermodynamic calculation of the oxide scale thickness gives a value of $10 \mu \mathrm{m}$ after a testing time of $900 \mathrm{~s}$.

As mentioned earlier (Section 3.2), the calculated residual stresses in the hematite layers are compressive at room temperature. This result may be related to the following three observations.

- The surface oxide layer is hematite.

- The hematite scale is about $6 \mu \mathrm{m}$.

- The hematite scale is in compression at room temperature. So the internal stresses may explain the macroscopic circular crack of the disc scale in the center of the wear track.

So we can suppose that at high temperature the initial friction contact of the disc is established on the hematite scale which is very textured.

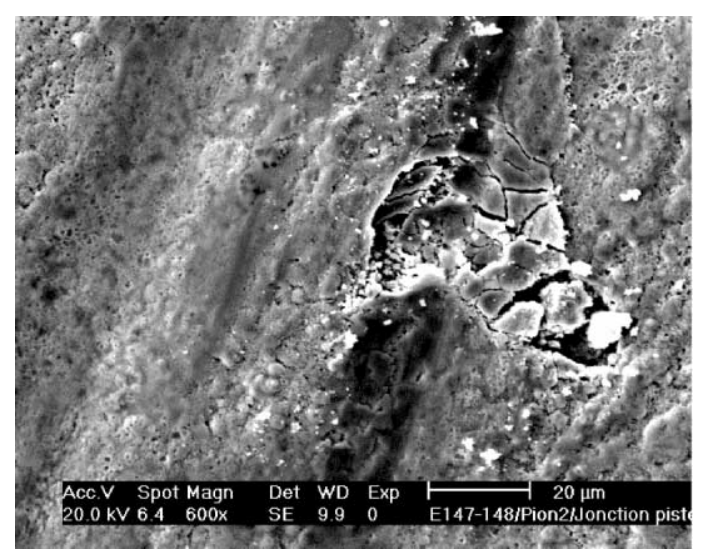

Fig. 17. Pin micrograph - observation of wear debris.

\subsection{Tribological behavior of oxide scales}

For both tests (series B and series C), the calculated heat flow between the pin and the disc surface is about $0.02 \mathrm{~W} / \mathrm{mm}^{2}$. Friction does not affect the duration of temperature stabilization in the pin (approximately $900 \mathrm{~s}$ ) nor the pin temperature level (approximately $700^{\circ} \mathrm{C}$ ) at $1 \mathrm{~mm}$ from the wear surface. It does not drastically increase the contact temperature.

The mean friction coefficient is less important when the test is performed under high temperature in comparison to room temperature. So, the oxide scale decreases the coefficient of friction and it can be considered as a solid lubricant.

Furthermore, under high load $(10 \mathrm{~N})$, the friction coefficient decreases, for the same conditions of temperature. In this case (Fig. 18), the plastically deformed layer at the pin surface is thicker than in the case of $2.5 \mathrm{~N}$ (Fig. 15c). It seems that the bulk behavior of oxide would be more important in friction phenomenon than the surface oxide.

At the end of series B like series C, the wear tracks present the same features. The contact, therefore, friction, is sustained by the nodules and the plastic deformation of the wear tracks. The real contact surface presents a glazed aspect. It is very different (lower) from the apparent surface of contact. EDS spectra show only iron oxides on the pin wear track, whereas this cast iron, outside the friction zones, always presents oxides rich in $\mathrm{Cr}, \mathrm{Mn}, \mathrm{V}$ and $\mathrm{Nb}$. This analysis would indicate a transfer from the disc oxide scale to the pin surface.

EDS spectra show also that the plastically deformed areas consist exclusively of iron oxides. We never observed plastic deformation of presumed oxidized carbides.

No mechanically shear ruptured oxide layer is observed. Nevertheless, a plastic flow of oxide is observed on the contact surface of the disc and the pin. This plastic deformation is not observed in the bulk oxide layer. In fact, the superficial plastic deformation of the oxide layer, formed on the pin and disc surfaces, reinforces the idea that the coefficient of friction, in our case, is a Coulomb type.

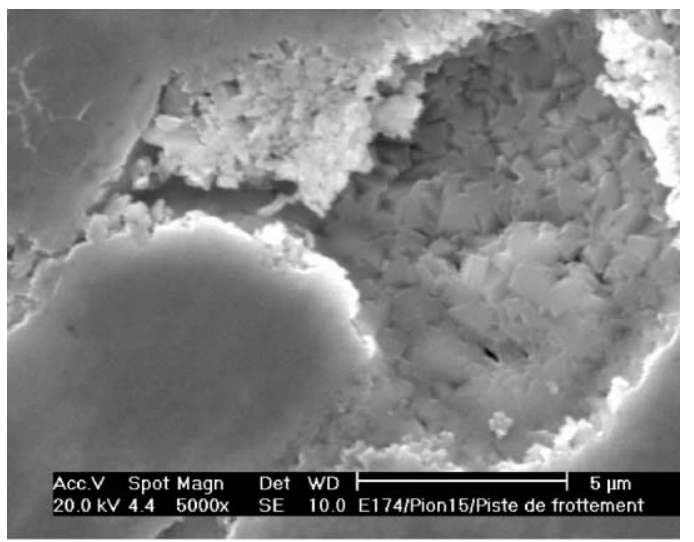

Fig. 18. Pin micrograph - plastically deformed layer of iron oxide $\left(F_{n}=10 \mathrm{~N}\right)$. 
(a)

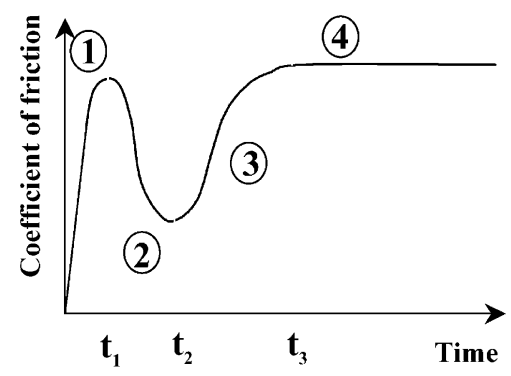

(b)

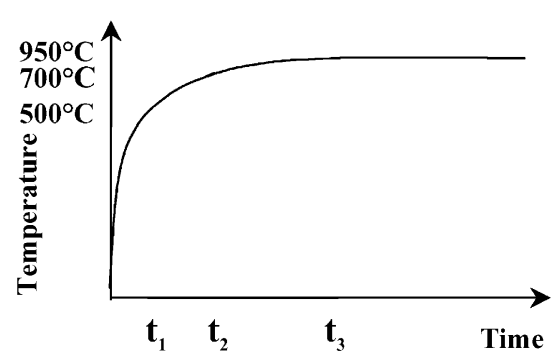

Fig. 19. Evolution of friction coefficient in the case of the non stabilized temperature in the pin (a) and evolution of the superficial temperature of the pin calculated by a numerical model (b).

\subsection{Interpretation of the friction coefficient evolution for initial metal-oxide contact}

In experiments without stabilization of the temperature in the pin (series C), we can assume that the non-stationary period of the coefficient of friction, observed in the beginning of the test, is due to the formation of iron oxide layers at the pin surface. This non-stationary period was also observed by other authors [13]. The average steady friction value is equal to one of the series $B$.

In the case of tests in non stabilized temperature (Fig. 19a), the general evolution of the friction coefficient can be associated with the change of the pin surface temperature, calculated from a numerical inverse method of integration (Fig. 19b). We can identify four significant stages.

Stage (1) concerns the increase of the friction coefficient at the start of the tribological test. Here, sliding is assumed by the cast iron "A" on AISI $1018950^{\circ} \mathrm{C}$ oxidized steel. So, initially, contact is metal on oxide.

While the friction coefficient increases, the surface pin temperature rises to $500^{\circ} \mathrm{C}$. At this temperature, pin surface oxidation occurs. The pin material is an alloyed cast iron containing $\mathrm{Nb}$ carbides. Indeed, these carbides are very numerous at the surface of the cast iron, and they oxidize at $430^{\circ} \mathrm{C}$. In the same way, the carbides of $\mathrm{V}, \mathrm{Fe}$ and Mo can also be oxidized at temperatures lower than $500^{\circ} \mathrm{C}$. In addition, the $\mathrm{Nb}$ carbides, during oxidation, form excrescences perforating the surface oxide scale.

In stage (2), the coefficient of friction decreases. So, the oxide scales play a lubricant role. We can verify, with interruption of the test, transfer of the oxidized $\mathrm{Nb}$ carbides on the disc and the onset of debris compaction without plastic deformation. Debris formation is a consequence of the attrition phenomenon which precedes adhesion. It is facilitated by shearing and abrasion. Transfer of oxidized $\mathrm{Nb}$ carbides was made possible by the porous columnar-like microstructure of iron oxides on the disc surface (Fig. 9b). This microstructure could contribute to mechanical adhesion. The debris compaction seems to result in the diminution of contact pressures and, thus, a reduction of the coefficient of friction. The calculated pin temperature then reaches $700^{\circ} \mathrm{C}$.

In stage (3), the friction coefficient increases. The tribosystem initiates transfer to the pin, more precisely the transfer of iron oxides formed on the surface of the disc. This transfer may occur on the top of the agglomerated particles, on the top of sponge microstructure iron oxides and on the top of $\mathrm{Nb}$-rich excrescences. Reciprocally on the disc surface, there are zones of compaction of oxidized $\mathrm{Nb}$ carbide debris coming from the pin. These zones also constitute an area of mechanical adhesion of iron oxides. The increase of the coefficient of friction is consecutive with the mechanical adhesion, plastic deformation and abrasion of iron oxides, from the pin toward the disc and from the disc toward the pin. When the contact is mechanically and chemically established, the pin surface temperature is steady, and estimated by calculation to be $950^{\circ} \mathrm{C}$.

In stage (4), the stationary regime of the friction coefficient begins as in series B tests. During these experiments, the phases of pin oxidation during sliding are not revealed and the transfer phenomena are much faster. For these reasons, in the series B tests, the stationary state of the friction coefficient occurs more quickly.

At the end of this part, whatever the type of test, a new microstructure is carried out in the contact zones, initially plastically deformed. This new microstructure that we call "under-cells" seems to result from strain-hardening by shearing of the friction surface. The mechanisms of the growth of these "under-cells" are not well known yet.

\section{Conclusion}

The high temperature pin on disc tribometer allows study of friction coefficient variations during the oxidation of the samples.

Oxide scale plays a lubricant role in friction. During high temperature experiments $\left(950^{\circ} \mathrm{C}\right)$, the friction coefficient evolution depends on the temperature stabilization time in the pin before sliding. Following two friction regimes are observed. 
- Low friction variation when the oxide scale is already formed on the pin before sliding.

- Large friction variation when the pin oxide scale grows during friction.

In both cases, wear track features, after friction coefficient stabilization, are the same. We observe plastically deformed zones exclusively made of iron oxides (even on the pin) and oxidized carbide agglomerates (even on the disc). So, we can conclude, there is transfer between the two specimens. The contact is established at the interface of the pin and disc and not in the bulk oxide scale.

The aim of this study is to understand the first step of friction between the roll and the slab in hot rolling. We try to understand the influence of roll oxidation on wear mechanisms and friction values. This work will go on with the tribological study of different cast irons used as "roll" material.

\section{Acknowledgements}

The authors would like to thank FORCAST Society for their contribution to the study and $\mathrm{Mr}$ Beguin of
Ecole Nationale d'Ingénieurs de Tarbes for the X-ray analysis.

\section{References}

[1] E. Felder, Rev. Met. 12 (1984) 931-942.

[2] J. Bocquet, 37èmes Journées du Cercle d'Etude des Métaux, Albi, France, 1998.

[3] C. Vergne, C. Boher, C. Levaillant, R. Gras, 38èmes Journées du Cercle d'Etude des Métaux, Liège, Belgium, 1999.

[4] A. Magnée, C. Gaspard, M. Gabriel, Metallurgical Reports, Vol. 25, CRM ED., Lavoisier, 1980, pp. 25-39.

[5] P.A. Munther, J.G. Lenard, J. Mater. Process Technol. 88 (1999) 105-113.

[6] D.T. Blazevic, in: Proceedings of the 37th MWSP Conference, Vol. 3, ISS-AIME, 1996, pp. 33-38.

[7] C. Liu, J.L. Lebrun, Mater. Sci. Eng. A160 (1993) 113-126.

[8] Arts \& Métiers, Publications Scientifiques et Techniques, 1981.

[9] R. Trimbitasu, Internal Report of EMAC, 2000.

[10] S.J. Bull, Oxid. Met. 49 (12) (1998) 1-17.

[11] H.E. Evans, Intern. Mat. Rev. 40 (1) (1995).

[12] F.P. Bowden, D. Tabor, The Friction and Lubrication of Solids, Oxford Science Publications, Oxford, 1986.

[13] F.H. Stott, J. Glascott, G.C. Wood, Wear 97 (1984) 93-106. 